\title{
A study on the influence of hot press forming process parameters on mechanical properties of green composites using Taguchi experimental design
}

\author{
G. Bhanu Kiran ${ }^{1 *}$, K. N. S. Suman ${ }^{2}$, N. Mohan Rao ${ }^{3}$, R. Uma Maheswara Rao ${ }^{4}$ \\ ${ }^{1 *}$ Department of Mechanical Engineering, GITAM University, Visakhapatnam, INDIA \\ ${ }^{2}$ Department of Mechanical Engineering, Andhra University, Visakhapatnam, INDIA \\ ${ }^{3}$ Department of Mechanical Engineering, JNT University, Kakinada, INDIA \\ ${ }^{4}$ Department of Mechanical Engineering, GMRIT, Rajam, INDIA \\ *Corresponding Author: e-mail: bk_1381@yahoo.co.in, Tel +91-891-2720438
}

\begin{abstract}
Green composites made from natural fibers, and biopolymers offer a potential alternative to the petroleum-based materials, that are currently being used in many nonstructural applications. In spite of being biodegradable and eco friendly, range of applications is limited due to poor mechanical properties. Hence an attempt is made in this work to improve the mechanical properties of green composites by optimizing the hot press forming process parameters using Taguchi experimental design. Process parameters such as temperature, pressure, heating time, cooling system and recrystallization soak time were chosen for evaluation by Taguchi method. An $\mathrm{L}_{16}$ orthogonal array was chosen for the design of experiments. The optimum combination of process parameters is obtained by using the analysis of the signal-to-noise ratio. The levels of importance of process parameters on mechanical properties were determined by using analysis of variance (ANOVA). The variation of tensile, flexural and impact properties with process parameters were mathematically modeled using the regression analysis. Finally, the presented models are also verified by a set of verification tests.
\end{abstract}

Keywords: Green composites, Hot press forming, Taguchi method, Scanning electron microscope.

\section{Introduction}

Green composites composed of biopolymers derived from renewable resources and cellulose fibers have been gathering much attention from the stand point of protection of the environment from plastic disposal problem and saving petroleum resources (LaMantia and Morreale, 2011). These fully biodegradable and eco friendly materials find their way in several structural and nonstructural applications where they are not subjected to high loads. Poor wettability, high moisture absorption capability, insufficient adhesion between hydrophilic fiber \& hydrophobic polymer, and improper processing methods and conditions are the key factors that are limiting the applications of these materials. Extensive research was carried out by various researchers through the years, on improving the fiber matrix adhesion by various fiber surface treatments (Shibata et al, 2008; Oksman et al, 2003; Arbeliaz et al., 2006; Avella et al., 2007; Sreekumar et al., 2011; Swapan et al., 2011). However, these techniques were not cost effective and improvement in mechanical properties was limited in most of the cases. In addition to fiber/matrix adhesion, processing method and processing conditions are also the key elements that have profound influence on mechanical properties of green composites, as natural fibers are thermally unstable.

Garkhail et al. (1999) have demonstrated that mechanical properties of PHB and flax fiber green composites are greater when processed using hot press forming (film stacking) in comparison to injection molding. Thermal degradation of natural fibers occurs in injection moulding process, as they are subjected to two heating cycles, one to create compound and the other one when it is injected. Furthermore, these fibers are subjected to the high amount of shearing during the injection process, which leads to fiber damage. During hot press forming process, fibers are heated only once and are not subjected to any shearing. Consequently, it becomes easier to limit the damage of the fibers (Bodros et al., 2007). Hence hot press forming process has been used in this work. 
Processing parameters significantly influences the properties and interfacial characteristics of the composites. Therefore, suitable processing parameters must be carefully selected in order to yield the optimum composite products (Ku et al., 2011). Most important hot press forming parameters that influence the mechanical properties are temperature, pressure and heating time. Ochi (2008) studied the effect of processing temperature on tensile and flexural strengths of unidirectional kenaf/PLA composites and found the optimum processing temperature to be $160^{\circ} \mathrm{C}$. Bernard et al. (2011) investigated the effect of processing parameters including temperature and speed on mechanical properties of kenaf fiber plastic composites and found a new trend in processing parameters of long kenaf fiber plastic composites. Takagi et al (2008) studied the effect of processing pressure on the flexural strength and moduli of the green composites. They found an increase in flexural strength and modulus with increasing molding pressure. Medina et al. (2009) showed the dependence of mechanical properties of natural fiber reinforced composites on the process pressure. Rassmann et al. (2010) observed an increase in tensile and flexural strength with processing pressure. Placket et al. (2003) demonstrated that tensile properties of PLA/Jute fiber composite are greater, when processed at lower heating time. In addition, cooling system/rate, pre heating time, recrytallization soak time, etc. will also have an influence on the mechanical properties of the thermoplastic composites (Rezaei et al., 2006). Hence an attempt is made to analyze the impact of hot press forming process parameters on mechanical properties of green composites. For this purpose, an inexpensive and easy to operate experimental strategy based on Taguchi's parameter design has been adopted to study the effect of various process parameters. This experimental procedure has already been successfully applied for parametric appraisal in the wire electrical discharge machining process (Mahapatra et al., 2007), drilling of metal matrix composites (Basavarajappa, et al., 2006), wear behavior of polymer matrix composites (Patnaik et al., 2008) and erosion response of hybrid composites (Patnaik et al., 2009). The present study aims at studying the influence of process parameters on mechanical properties of green composites using the Taguchi method. Further, analysis of variance is done to identify the most significant process parameters.

\section{Experimental Details}

2.1 Materials: Biodegradable polymer, Polylactide (GCS PLA 4320) supplied by Green chemical Co. Ltd., south Korea, was used as a matrix in this work. Physical, mechanical and thermal properties of the virgin matrix obtained through various tests done according to ASTM standards were given in Table 1. Jute fiber with a density of $1.29 \mathrm{gm} / \mathrm{cm}^{3}$ and an average diameter $60 \mu \mathrm{m}$ was used for reinforcing polylactide. Mean tensile strength obtained from single fiber tests was found to be $432 \pm 41 \mathrm{~N} / \mathrm{mm}^{2}$.

Table 1. Physical, mechanical and thermal properties of Polylactide

\begin{tabular}{|l|l|}
\hline Density $\left(\mathrm{g} / \mathrm{cm}^{3}\right)$ & 1.25 \\
\hline Melt flow Index $(\mathrm{g} / 10 \mathrm{~min})$ & 15 \\
\hline Tensile strength $(\mathrm{MPa})$ & 42 \\
\hline Tensile Modulus $(\mathrm{Gpa})$ & 1.7 \\
\hline Flexural strength(Mpa) & 85 \\
\hline Melting temperature $\left({ }^{0} \mathrm{C}\right)$ & 172 \\
\hline Glass Transition temperature $\left({ }^{0} \mathrm{C}\right)$ & 65 \\
\hline Melt crystallization temperature $\left({ }^{0} \mathrm{C}\right)$ & 101.85 \\
\hline Cold crystallization temperature $\left({ }^{0} \mathrm{C}\right)$ & 90.97 \\
\hline
\end{tabular}

2.2 Composite Fabrication: In order to remove the absorbed and adsorbed moisture and thereby to prevent the void formation, jute fiber and PLA matrix were dried in the vacuum at $80^{\circ} \mathrm{C}$ for 6hours before specimen fabrication. In this study, Jute fiber/PLA green composites were fabricated by hot press forming process. This method consists of heating and compressing a stack of polymer films and fiber mats for a measured amount time.

Initially PLA films were prepared by heating and compressing PLA granules at $170^{\circ} \mathrm{C}$. Film thickness was maintained constant by using picture frame of $0.7 \mathrm{~mm}$ thick. Finally, green composites were moulded from a stack of PLA films interleaved with unidirectional stitched jute fiber mats. The stack was put on a compression moulding machine equipped with heating plates. The assembly is heated and pressed once the polymer has melted. Then, the composite cooled to melt crystallization temperature and held at that temperature for a measured amount of time and again cooled to room temperature under constant pressure. The ratio between the mass of the jute fiber mats and of PLA films determines the fiber weight fraction in the composite. All the composites were fabricated with $20 \%$ fiber weight fraction. Processing cycle is shown in Figure 1.

2.3 Tensile Strength: Tensile tests were conducted using a universal testing machine (INSTRON 3385). Dumbbell shaped tensile test specimens were cut from the compression moulded plates using a milling machine. Tensile tests were carried out in accordance with ASTM D 638 (Type I) with a cross head speed of $5 \mathrm{~mm} / \mathrm{min}$. 
2.4 Flexural Strength: Three point bending tests were conducted using a universal testing machine (INSTRON 3385). Tests were carried out in accordance with ASTM D 790 with a cross head speed of $2 \mathrm{~mm} / \mathrm{min}$. Flexural strength was determined using the following equation:

$$
F S=\frac{3 P L}{2 b t^{2}}
$$

Where $\mathrm{p}$ is the maximum load, $\mathrm{L}$ is the span length, $\mathrm{b} \& \mathrm{t}$ are width and thickness of the specimen.

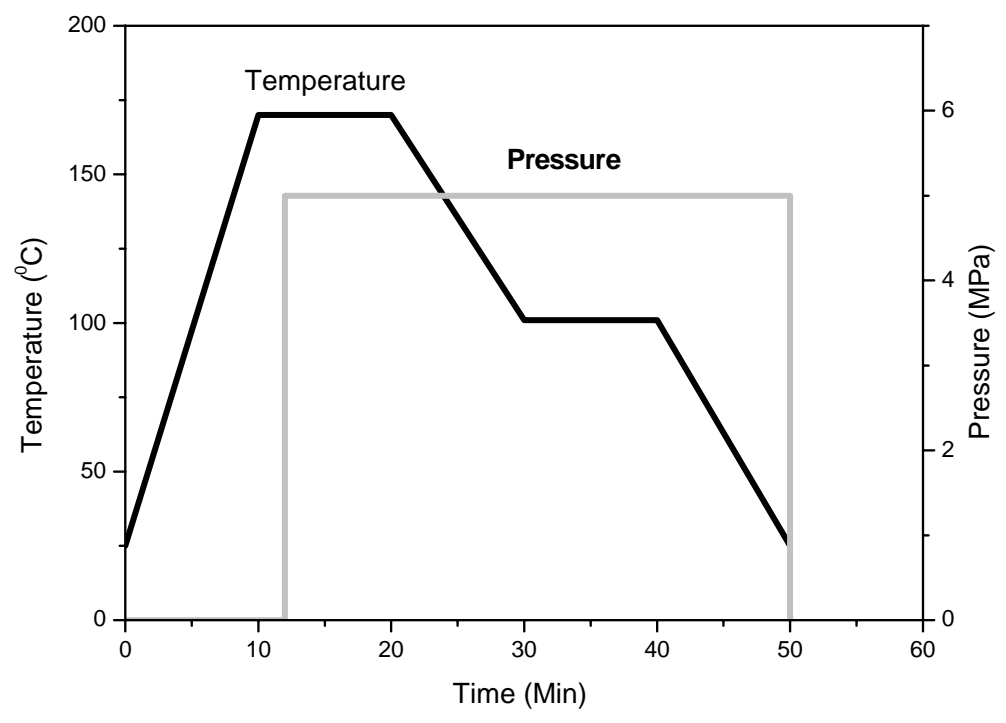

Figure 1. Processing cycle of jute fiber/Polylactide composite

2.5 Impact strength: Notched Izod Impact tests were carried out using low energy instrumented Impact tester (Tinius Olsen). Tests were done as per ASTM D 256. The standard specimen for ASTM D256 is 64 x $12.7 \times 3 \mathrm{~mm}^{3}$, and the depth under the notch is $10.2 \mathrm{~mm}$. The pendulum impact testing machine ascertains the notch impact strength of the material by shattering the V-notched specimen with a pendulum hammer measuring the spent energy and relating it to the cross section of the specimen.

2.6 Experimental Design: The design of experiments is a powerful tool for modeling and analyzing the influence of control factors on performance output. The most significant stage in the design of experiments lies in the selection of the control factors. An, exhaustive literature review on mechanical performance of polymer composites reveals that parameters such as, temperature, pressure, heating time cooling system and time at melt crystallization temperature (recrystallization soak time) largely influence the mechanical properties of polymer composites. The impact of these five parameters is studied using $\mathrm{L}_{16}$ orthogonal design. Here, only the main effects of the factors are of interest, and their interactions are excluded from data analysis. The processing conditions under which green composites are fabricated are given in Table 2. All the five process parameters have four levels. In this work four cooling systems have been used for comparison. Average cooling rate in forced convection 1 (circulating water through the hot plates) is $16^{0} \mathrm{C} / \mathrm{min}$. In forced convection 2 an average cooling rate of $7^{0} \mathrm{C} / \mathrm{min}$ is obtained by blowing cool air between the hot plates. Whereas in forced convection 3, an average cooling rate of $4^{0} \mathrm{C} / \mathrm{min}$ is obtained by blowing air at room temperature. In natural convection average cooling rate is $1^{0} \mathrm{C} / \mathrm{min}$. In a full factorial experiment design, it would require $4^{5}=1024$ combination of runs to study five parameters each at four levels, whereas Taguchi's factorial experiment approach reduces it to only 16 runs, offering a great advantage in terms of experimental cost and time. The experimental observations are further transformed into a signal-to-noise $(\mathrm{S} / \mathrm{N})$ ratios. Based on the type of performance characteristics, one has to select the suitable $\mathrm{S} / \mathrm{N}$ ratio. In this study, "higher is better" is considered to maximize tensile, flexural and impact strength of the green composites. For this case, $\mathrm{S} / \mathrm{N}$ ratio is calculated as a logarithmic transformation of loss function as shown below

$$
\text { Higher is better characteristic: } \mathrm{S} / \mathrm{N}(\eta)=-10 \log \frac{1}{n}\left(\sum \frac{1}{y^{2}}\right)
$$

where $\mathrm{n}$ is the number of observations and $\mathrm{y}$ is the observed data. 
The designed experiments are shown in Table 3. Each column represents a process parameter, whereas a row stands for processing condition, which is nothing but a combination of parameter levels. The mechanical tests were carried out on these experiments and replicated three times.

Table 2. Levels of the process parameters used in the experiment.

\begin{tabular}{|l|c|c|c|c|}
\hline \multirow{2}{*}{ Process parameters } & \multicolumn{4}{|c|}{ Levels } \\
\cline { 2 - 5 } & 1 & 2 & 3 & 4 \\
\hline A: Temperature ( $\left.{ }^{0} \mathrm{C}\right)$ & 170 & 180 & 190 & 200 \\
\hline B: Pressure (Mpa) & 2.5 & 5 & 7.5 & 10 \\
\hline C: Heating time (min) & 5 & 10 & 15 & 20 \\
\hline D: Cooling System & $\begin{array}{c}\text { Forced } \\
\text { Convection 1 }\end{array}$ & $\begin{array}{c}\text { Forced } \\
\text { Convection 2 }\end{array}$ & $\begin{array}{c}\text { Forced } \\
\text { Convection 3 }\end{array}$ & $\begin{array}{c}\text { Natural } \\
\text { Convection }\end{array}$ \\
\hline $\begin{array}{l}\text { E: Recrystallization soak } \\
\text { time (min) }\end{array}$ & 0 & 5 & 10 & 15 \\
\hline
\end{tabular}

Table 3. Experimental design using the $\mathrm{L}_{16}$ orthogonal array.

\begin{tabular}{|c|c|c|c|c|c|c|c|c|c|c|c|}
\hline $\begin{array}{c}\text { Expt. } \\
\text { No. }\end{array}$ & $\mathrm{A}$ & $\mathrm{B}$ & $\mathrm{C}$ & $\mathrm{D}$ & $\mathrm{E}$ & $\begin{array}{c}\text { Tensile } \\
\text { Strength } \\
(\mathrm{MPa})\end{array}$ & $\begin{array}{c}\text { S/N } \\
\text { Ratio } \\
\mathrm{dB}\end{array}$ & $\begin{array}{c}\text { Flexural } \\
\text { Strength } \\
(\mathrm{MPa})\end{array}$ & $\begin{array}{c}\text { S/N } \\
\text { Ratio } \\
\mathrm{dB}\end{array}$ & $\begin{array}{c}\text { Impact } \\
\text { Strength } \\
\mathrm{KJ} / \mathrm{m}^{2}\end{array}$ & $\begin{array}{c}\text { S/N } \\
\text { Ratio } \\
\mathrm{db}\end{array}$ \\
\hline 1 & 170 & 2.5 & 5 & 16 & 0 & 69.4 & 36.83 & 94.5 & 39.50 & 28.6 & 29.12 \\
\hline 2 & 170 & 5 & 10 & 7 & 5 & 57.4 & 35.18 & 90.5 & 39.13 & 32.6 & 30.26 \\
\hline 3 & 170 & 7.5 & 15 & 4 & 10 & 35.8 & 31.04 & 57.3 & 35.16 & 36.3 & 31.17 \\
\hline 4 & 170 & 10 & 20 & 1 & 15 & 24.2 & 27.63 & 24.5 & 27.79 & 38.9 & 31.79 \\
\hline 5 & 180 & 2.5 & 10 & 4 & 15 & 34.3 & 30.61 & 42.5 & 32.58 & 33.3 & 30.43 \\
\hline 6 & 180 & 5 & 5 & 1 & 10 & 44.5 & 32.92 & 50.8 & 34.11 & 38.1 & 31.60 \\
\hline 7 & 180 & 7.5 & 20 & 16 & 5 & 39.8 & 31.97 & 45.5 & 33.16 & 23.8 & 27.50 \\
\hline 8 & 180 & 10 & 15 & 7 & 0 & 40.6 & 32.17 & 39.2 & 31.87 & 23.4 & 27.31 \\
\hline 9 & 190 & 2.5 & 15 & 1 & 5 & 27.3 & 28.68 & 33.4 & 30.47 & 28.3 & 29.01 \\
\hline 10 & 190 & 5 & 20 & 4 & 0 & 28.1 & 28.98 & 38.1 & 31.58 & 25.7 & 28.18 \\
\hline 11 & 190 & 7.5 & 5 & 7 & 15 & 28.8 & 29.15 & 33.5 & 30.47 & 30.1 & 29.57 \\
\hline 12 & 190 & 10 & 10 & 16 & 10 & 29.6 & 29.36 & 30.1 & 29.55 & 24.2 & 27.64 \\
\hline 13 & 200 & 2.5 & 20 & 7 & 10 & 24.8 & 27.86 & 26.6 & 28.50 & 19.8 & 25.96 \\
\hline 14 & 200 & 5 & 15 & 16 & 15 & 26.4 & 28.30 & 35.4 & 30.95 & 22.1 & 26.83 \\
\hline 15 & 200 & 7.5 & 10 & 1 & 0 & 25.3 & 28.04 & 30.3 & 29.60 & 23.9 & 27.55 \\
\hline
\end{tabular}

\section{Results and Discussions}

This section, discusses the experimental findings using the main effect plots, signal to noise ratio and analysis of variance (ANOVA) to estimate the effect of various hot press forming process parameters on tensile, flexural and impact strengths of green composites. Based on the $\mathrm{S} / \mathrm{N}$ ratio and ANOVA results, optimal combination of process parameters and their contributions have been obtained and verified. Furthermore, the variation of mechanical properties of green composites with process parameters is modeled mathematically using the multiple linear regression analysis method.

3.1 Data analysis: Tensile, flexural, impact strengths of the designed experiments are summarized in Table 3. The main effect plots in Figure 2 show the magnitude of the effect of each process parameter on the tensile strength. Data mean is used to determine each process parameter effect. Figure 2 a shows the effect of processing temperature on the tensile strength. Decrease in 
tensile strength can be observed with an increase in processing temperature. This may be due to thermal degradation of thermally sensitive jute fiber (Mohanty et al, 2000). In general, natural fiber thermal degradation processes commence at temperatures as low as $120^{\circ} \mathrm{C}$, resulting in a decomposition of waxes. Temperatures around $180^{\circ} \mathrm{C}$ lead to a decomposition of pectin, temperatures of approximately $230^{\circ} \mathrm{C}$ have the consequence of a decomposition of cellulose (Ochi, 2008). This obviously leads to a non-reversible reduction of fiber strength, inevitably affecting the mechanical properties of the later composite. Figure $2 \mathrm{~b}$ presents the effect of processing pressure on the tensile strength. Maximum tensile strength is observed at $5 \mathrm{Mpa}$ and at further higher processing pressures decrease in tensile strength is observed. Higher processing pressure may cause damage to the fiber as well as leading to matrix starvation. Figure $3 \mathrm{~b}$ depicts the influence of heating time on the tensile strength. Length of heating time influences the wetting between matrix and fiber and also results in better impregnation of fiber in the matrix. Unlike to the expectations, tensile strength decreased with an increase in heating time. This may be due to thermal degradation of the jute fiber, when exposed to higher heating time. Ochi (2006) observed $20 \%$ strength reduction due to thermal degradation, in manila hemp fiber exposed to temperature of $180^{\circ} \mathrm{C}$ for 20 mins. Influence of cooling rate on the tensile is shown in Figure $2 \mathrm{~d}$. Reduction in tensile strength is observed, when the mould is cooled slowly (lower cooling rates). At lower cooling rates, since the material stayed at the crystallization temperature for a long time, shperulite formation will take place (Figure 3a). These shperulites cause local stress concentration and results in the reduction of tensile strength. At higher cooling rates, crystallite growth is suppressed and thus results in formation of lamellar structure as shown in Figure 3b. Figure 2e represents the impact of recrystallization soak time (time at melt crystallization temperature). It is found that, recrystallization soak time has an adverse effect on the tensile strength. This may be due to the formation of spherulitic structure, when the mould is held at melt crystallization temperature for the measured amount of time.
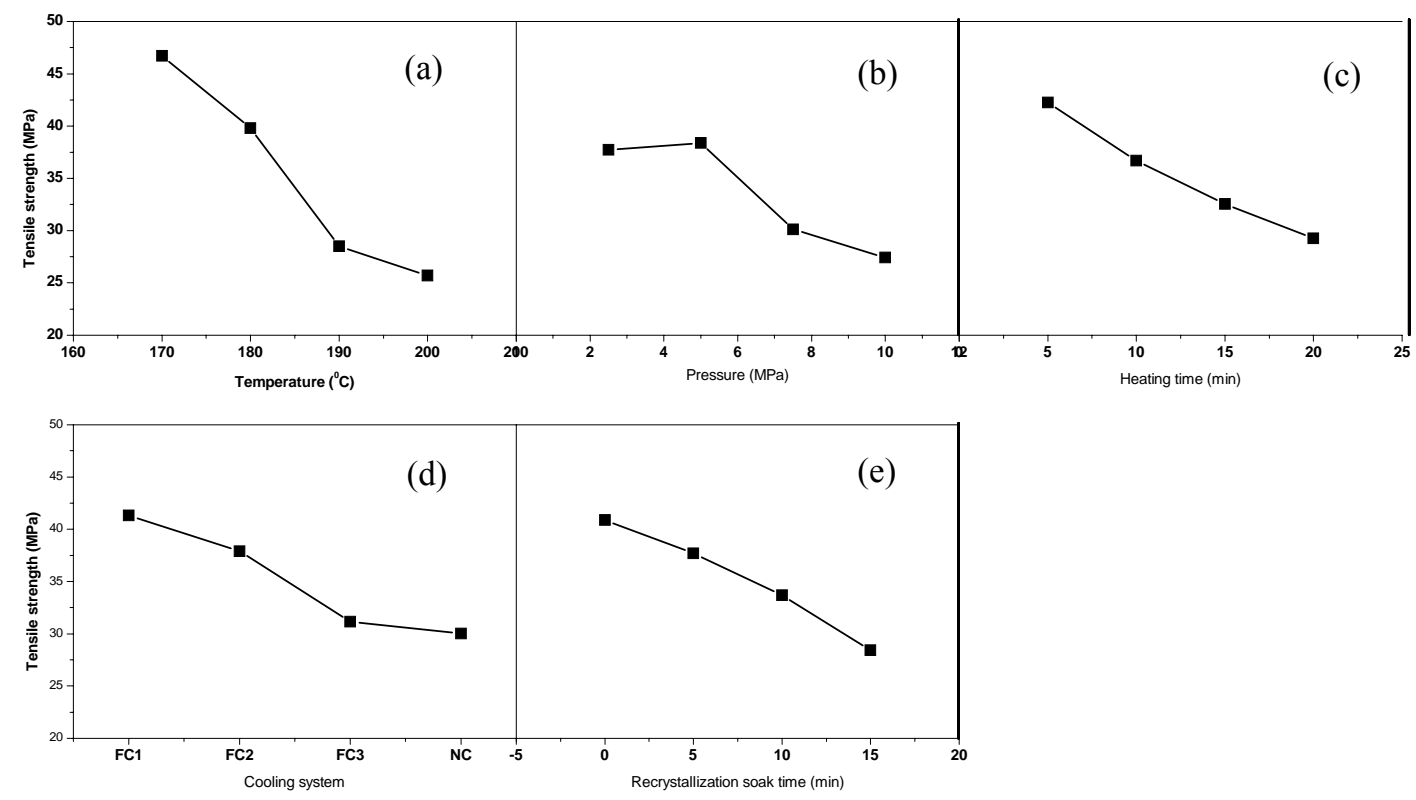

Figure 2 a-e. Effect of process parameters on tensile strength (MPa)
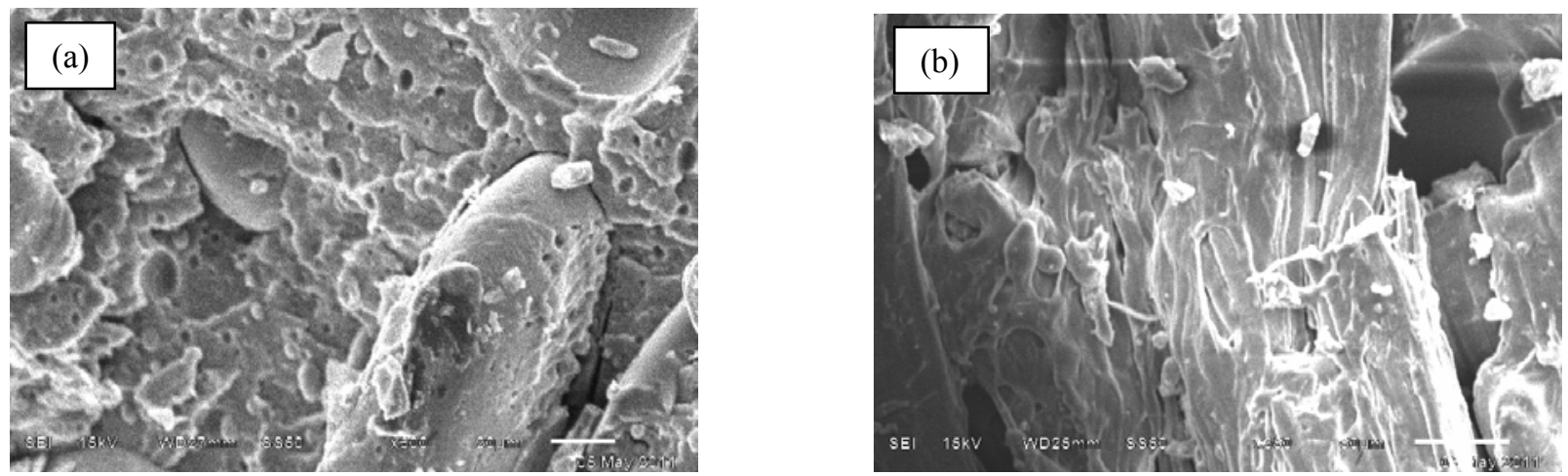

Figure 3. SEM images showing (a) Spherulitic structure for slowly cooled samples (b) Lamellar structure for rapidly cooled samples 

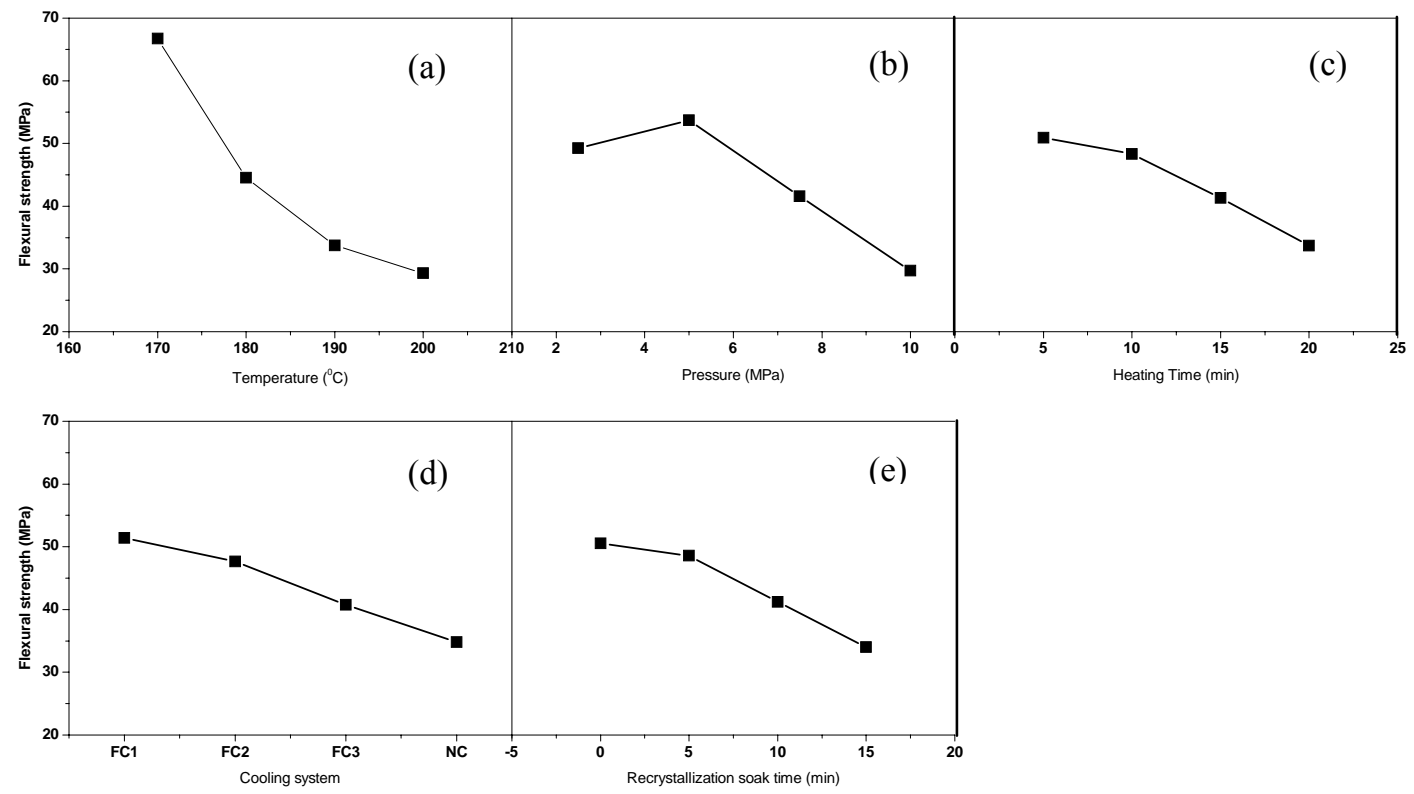

Figure 4 a-e. Effect of process parameters on flexural strength (MPa)
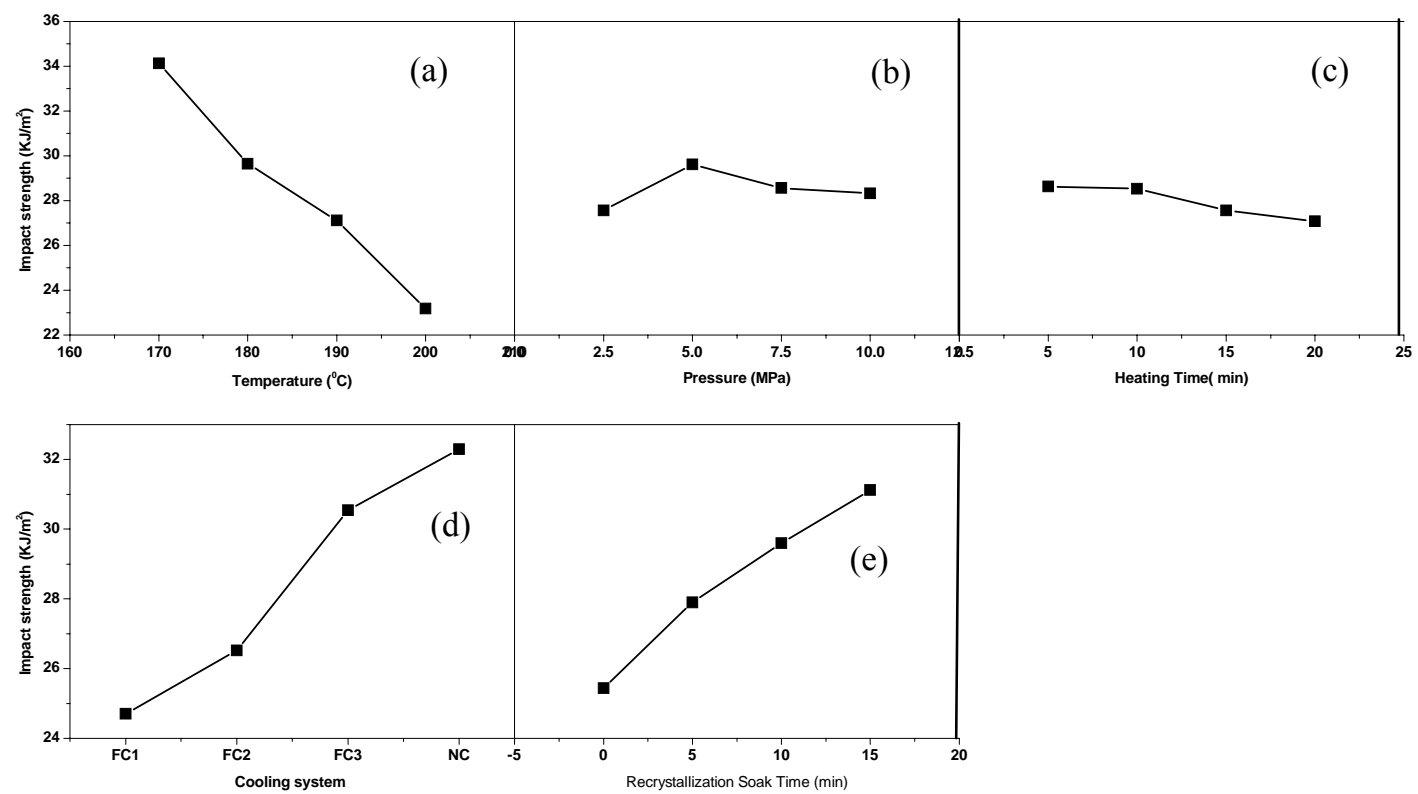

Figure 5 a-e. Effect of process parameters on Impact strength $\left(\mathrm{KJ} / \mathrm{m}^{2}\right)$

Impact of hot press forming processing parameters on the flexural strength of the jute fiber/ Polylactide composites is given in main effect plots (Figure 4). Figure $4 \mathrm{a}$ indicates that the processing temperature has the most significant effect on the flexural strength of the green composites. Bodros et al (2007) suggested that viscosity of thermoplastic used in the hot press forming process had to be close to $100 \mathrm{~Pa}$ s, for better impregnation of the fibers in the matrix. Better impregnation leads to enhancement of flexural strength. Hence processing temperature has to be at least $30^{\circ} \mathrm{C}$ above the melting temperature in order to have the lowest viscosity possible and better flexural strength. However, the reduction of flexural strength at higher processing temperatures may 
be due to thermal degradation of the natural fiber. Figure 4b-e present the effect of processing pressure, heating time, cooling rate and recrystallization soak time. Reasons given for variation of tensile strength with respect to these process parameters are also appropriate for flexural strength.

Figure 5 depicts the plot of process parameters effect on impact strength of the green composite. Variation of impact strength with respect to processing temperature, pressure and heating time is given in Figures 5a-c. The Influence of these three process parameters on impact strength is similar to that of tensile and flexural strengths. Figure $5 \mathrm{~d}$ shows the influence of cooling rate on the impact strength of the green composites. Unlike to the tensile and flexural strengths, lower cooling rates resulted in higher impact strength. Deboning, pull out and fiber fractures are the mechanisms of energy absorption during impact. Higher energy absorbing capacity at lower cooling rates may be due to debonding at the interfaces between spherulites and the matrix. At higher cooling rates formation of spherulites is suppressed, and thereby energy absorbed by debonding mechanism is minimal. Effect of recrystallization soak time on impact strength is shown in Figure 5e. Spherulitic structure formed at higher recrystallization soak time is responsible for the improvement of impact strength.

3.2 S/N ratio analysis: To find the optimal parameter levels $\mathrm{S} / \mathrm{N}$ ratio analysis is used. $\mathrm{S} / \mathrm{N}$ ratio values for tensile strength, flexural strength and impact strength are presented in Tables 4-6 respectively. The largest value of $\mathrm{S} / \mathrm{N}$ ratio indicates the optimal processing condition. Analysis of the results leads to the conclusion that, optimal combination of process parameters for maximum tensile and flexural strength is A1, B2, C1, D1, E1, and for maximum impact strength is A1, B2, C1, D4, E4.

Table 4. $\eta$ Values $(\mathrm{dB})$ for tensile strength (MPa).

\begin{tabular}{|c|c|c|c|c|c|}
\hline Level & A:Temperature & B:Pressure & C:Heating time & D:Cooling system & $\begin{array}{c}\text { E:Recrystallization } \\
\text { soak time }\end{array}$ \\
\hline 1 & 32.669 & 30.997 & 31.794 & 31.616 & 31.504 \\
\hline 2 & 31.915 & 31.343 & 30.799 & 31.088 & 31.026 \\
\hline 3 & 29.043 & 30.050 & 30.048 & 29.727 & 30.296 \\
\hline 4 & 28.123 & 29.360 & 29.109 & 29.318 & 28.923 \\
\hline Delta & 4.546 & 1.983 & 2.685 & 2.298 & 2.581 \\
\hline
\end{tabular}

Table 5. $\eta$ values $(\mathrm{dB})$ for flexural strength $(\mathrm{MPa})$

\begin{tabular}{|c|c|c|c|c|c|}
\hline Level & A:Temperature & B:Pressure & C:Heating time & D:Cooling system & $\begin{array}{c}\text { E:Recrystallization } \\
\text { soak time }\end{array}$ \\
\hline 1 & 35.394 & 32.762 & 32.943 & 33.291 & 33.138 \\
\hline 2 & 32.930 & 33.942 & 32.716 & 32.492 & 32.616 \\
\hline 3 & 30.519 & 32.097 & 32.111 & 31.752 & 31.829 \\
\hline 4 & 29.185 & 29.226 & 30.257 & 30.493 & 30.446 \\
\hline Delta & 6.209 & 4.717 & 2.686 & 2.798 & 2.692 \\
\hline
\end{tabular}

Table 6. $\eta$ values $(\mathrm{dB})$ for impact strength $\left(\mathrm{KJ} / \mathrm{m}^{2}\right)$

\begin{tabular}{|c|c|c|c|c|c|}
\hline Level & A:Temperature & B:Pressure & C:Heating time & D:Cooling system & $\begin{array}{c}\text { E:Recrystallization } \\
\text { soak time }\end{array}$ \\
\hline 1 & 30.585 & 28.631 & 29.708 & 27.774 & 28.042 \\
\hline 2 & 29.210 & 29.219 & 28.972 & 28.275 & 28.831 \\
\hline 3 & 28.602 & 28.947 & 28.581 & 29.584 & 29.092 \\
\hline 4 & 27.224 & 28.822 & 28.358 & 29.987 & 29.654 \\
\hline Delta & 3.361 & 0.587 & 1.350 & 2.212 & 1.612 \\
\hline
\end{tabular}

3.3 Analysis of variance: In order to find the relative contribution of hot press forming process parameters on tensile, flexural and impact strengths of the green composites, ANOVA is performed on experimental data. Tables 7-9 shows the results of ANOVA for the three output responses considered in this work. On comparing the percentage of contribution and ANOVA results for tensile strength (Table 7), one can observe that the processing temperature has greater influence than the remaining parameters, since this has the highest $\mathrm{F}$ value and percentage contribution. While the contribution of remaining process parameters is more or less same. In the case of flexural strength (Table 8), processing temperature and pressure have greater influence. Processing pressure contributes more to the flexural strength than that of the tensile strength, which may be due to the difference in failure mechanisms. In flexure mode failure occurs due to separation between fibers and matrix where as in tensile mode failure occurs due to fiber breakage. In the case of impact strength, temperature, cooling rate and recrystallization soak time are significant, whereas pressure and heating time are insignificant. 
Table 7. ANOVA for tensile strength $(\mathrm{MPa})$

\begin{tabular}{|c|c|c|c|c|c|c|}
\hline Source & DF & Seq SS & Adj SS & Adj MS & $F$ value & $\begin{array}{c}\text { Percentage } \\
\text { contribution }\end{array}$ \\
\hline A & 3 & 3469.03 & 3469.03 & 1156.34 & 220.40 & 45.81 \\
\hline B & 3 & 747.69 & 747.69 & 249.23 & 47.50 & 9.87 \\
\hline C & 3 & 1135.81 & 1135.81 & 378.60 & 72.16 & 14.99 \\
\hline D & 3 & 1017.46 & 1017.46 & 339.15 & 64.64 & 13.44 \\
\hline E & 3 & 1034.66 & 1034.66 & 344.89 & 65.74 & 13.66 \\
\hline Residual & 32 & 167.89 & 167.89 & 5.25 & & 2.217 \\
\hline Total & 47 & 7572.53 & & & & 100 \\
\hline
\end{tabular}

Table 8. ANOVA for flexural strength $(\mathrm{MPa})$

\begin{tabular}{|c|c|c|c|c|c|c|}
\hline Source & DF & Seq SS & Adj SS & Adj MS & F value & $\begin{array}{c}\text { Percentage } \\
\text { contribution }\end{array}$ \\
\hline A & 3 & 10018.13 & 10018.13 & 3339.38 & 896.93 & 49.47 \\
\hline B & 3 & 3966.76 & 3966.76 & 1322.25 & 355.15 & 19.59 \\
\hline C & 3 & 2157.73 & 2157.73 & 719.24 & 193.18 & 10.65 \\
\hline D & 3 & 1935.09 & 1935.09 & 645.03 & 173.25 & 9.55 \\
\hline E & 3 & 2054.37 & 2054.37 & 684.79 & 183.93 & 10.14 \\
\hline Residual & 32 & 119.14 & 119.14 & 3.72 & & 0.58 \\
\hline Total & 47 & 20251.23 & & & & 100 \\
\hline
\end{tabular}

Table 9. ANOVA for impact strength $\left(\mathrm{KJ} / \mathrm{m}^{2}\right)$

\begin{tabular}{|c|c|c|c|c|c|c|}
\hline Source & DF & Seq SS & Adj SS & Adj MS & F value & $\begin{array}{c}\text { Percentage } \\
\text { contribution }\end{array}$ \\
\hline A & 3 & 760.91 & 760.91 & 253.64 & 98.89 & 46.65 \\
\hline B & 3 & 26.19 & 26.19 & 8.73 & 3.40 & 1.61 \\
\hline C & 3 & 104.32 & 104.32 & 34.77 & 13.56 & 6.39 \\
\hline D & 3 & 443.37 & 443.37 & 147.79 & 57.62 & 27.18 \\
\hline E & 3 & 214.19 & 214.19 & 71.40 & 27.84 & 13.13 \\
\hline Residual & 32 & 82.07 & 82.07 & 2.56 & & 5.03 \\
\hline Total & 47 & 1631.06 & & & & 100 \\
\hline
\end{tabular}

3.4 Confirmation experiment: The optimal combination of process parameters has been determined in the previous analysis. However, the final step in any design of experiments approach is to predict and verify improvements in the observed values through the use of the optimal combination level of process parameters. The confirmation experiment is performed by conducting a test with optimum levels of the process parameters. $\mathrm{S} / \mathrm{N}$ ratios for the confirmation experiment can be calculated by using the equation 1. Subsequently, $\mathrm{S} / \mathrm{N}$ ratios for optimal combination of process parameters can be predicted using the following equation

$\eta_{\text {opt }}=\eta_{\mathrm{m}}+\sum_{j=1}^{k}\left(\eta_{\mathrm{j}}-\eta_{\mathrm{m}}\right)$

where:

$\eta_{\text {opt }} \quad$ Predicted $\mathrm{S} / \mathrm{N}$ ratio

$\eta_{\mathrm{m}} \quad$ Total mean of $\mathrm{S} / \mathrm{N}$ ratios

$\eta_{\mathrm{j}} \quad$ Mean $\mathrm{S} / \mathrm{N}$ ratio at optimum levels

$\mathrm{k} \quad$ Number of main design parameters that affect the quality characteristics

The predicted $\mathrm{S} / \mathrm{N}$ ratios are compared with the experimental $\mathrm{S} / \mathrm{N}$ ratios for all the three performance measures, and the error associated with each performance measure is shown in Table 10. Predicted and experimental S/N ratios for the three performance measures at the optimal combination of process parameters are higher than that of any other designed experiments in the orthogonal array. The experimental results confirm the validity of the Taguchi method for optimizing the hot press forming process parameters. Therefore, the tensile, flexural and impact strengths of the green composites can be improved by applying this approach. 
Table 10. Results of confirmation test

\begin{tabular}{|c|c|c|c|c|}
\hline $\begin{array}{c}\text { Performance } \\
\text { Measure }\end{array}$ & $\begin{array}{c}\text { Optimal } \\
\text { process } \\
\text { Parameter } \\
\text { settings }\end{array}$ & $\begin{array}{c}\mathrm{S} / \mathrm{N} \text { ratio } \\
\text { Predictive } \\
\text { values (dB) }\end{array}$ & $\begin{array}{c}\text { S/N ratio } \\
\text { experimental } \\
\text { values (dB) }\end{array}$ & $\begin{array}{c}\text { Error } \\
(\%)\end{array}$ \\
\hline Tensile strength & A1B2C1D1E1 & 37.16 & 37.48 & 0.86 \\
\hline Flexural strength & A1B2C1D1E1 & 40.66 & 40.07 & 1.45 \\
\hline Impact strength & A1B2C1D4E4 & 33.56 & 31.92 & 4.88 \\
\hline
\end{tabular}

3.5. Regression analysis: In this study, an attempt is made to derive the mathematical models for tensile, flexure and impact strengths of green composites (with $20 \mathrm{wt} \%$ jute fiber), as a function of hot press forming process parameters, by using multiple linear regression analysis. Equations 3-5 present the mathematical models for the three performance measures

Tensile strength $=192.65-0.74 A-1.32 B-0.864 C+0.77 D-0.83 E$

$$
\mathrm{r}^{2}=0.95
$$

Flexural strength $=304.51-1.23 A-2.83 B-1.18 C+1.04 D-1.14 E$

$$
\mathrm{r}^{2}=0.88
$$

Impact strength $=97.56-0.35 A+0.05 B-0.249 C-0.5 D+0.38 E$

$$
r^{2}=0.93
$$

The higher correlation coefficients $\left(\mathrm{r}^{2}\right)$ confirm the suitability of the models and correctness of the calculated constants. To test these models, experiments were performed by taking arbitrary set of factor combination and compared with the predicted values. Table 11 shows the verification of the test results. The predicted performance measures are compared with the experimental values, and a good agreement is observed. Thus the above mathematical models are important for fabrication of eco friendly green composites with superior properties.

Table 11. Results of verification test

\begin{tabular}{|c|c|c|c|c|}
\hline $\begin{array}{c}\text { Performance } \\
\text { Measure }\end{array}$ & $\begin{array}{c}\text { Process } \\
\text { Parameter } \\
\text { settings }\end{array}$ & $\begin{array}{c}\text { Predicted } \\
\text { values }\end{array}$ & $\begin{array}{c}\text { Experimental } \\
\text { values }\end{array}$ & $\begin{array}{c}\text { Error } \\
(\%)\end{array}$ \\
\hline \multirow{2}{*}{ Tensile strength } & A1B2C1D1E1 & 68.9 & 74.9 & 8.6 \\
\cline { 2 - 5 } & A2B2C2D2E2 & 45.5 & 43.1 & 5.5 \\
\hline \multirow{2}{*}{ Flexural strength } & A1B2C1D1E1 & 92.1 & 101.1 & 8.9 \\
\cline { 2 - 5 } & A2B2C2D2E2 & 58.7 & 54.4 & 7.9 \\
\hline \multirow{2}{*}{ Impact strength } & A1B2C1D1E1 & 29.1 & 31.1 & 6.1 \\
\cline { 2 - 5 } & A2B2C2D2E2 & 30.4 & 31.8 & 4.4 \\
\hline
\end{tabular}

\section{Conclusions}

The effects of hot press forming process parameters on mechanical properties of jute fiber reinforced green composites are experimentally investigated.

As the experimental results show, processing temperature has the most significant effect on all the three performance measures considered in this work. Processing pressure and heating time are significant for tensile and flexural strengths, while they are insignificant for impact strength. Effect of cooling rate and recrystallization soak time on the tensile, flexural and impact strengths are influential, but their contribution to the impact strength is more than that of the tensile and flexural strengths. Optimum parameter combinations for the maximum tensile, flexural and impact strengths are obtained by using $\mathrm{S} / \mathrm{N}$ ratios. Mathematical models for tensile, flexural and impact strengths of hot press formed green composites are successfully proposed for the selection of process parameters. This Taguchi method based approach for the finding out the significant hot press forming parameters during the fabrication of jute fiber based green composites provides efficient guide lines for manufacturing engineers.

From the present study, it is evident that the establishment of optimal combination of hot press forming parameters is very beneficial for manufacturing of green composites with better tensile, flexural an impact strength. Further research might attempt to consider the other performance criteria such as stiffness, elongation at break, density, toughness and degree of crystallinity as output parameters. Further improvement of mechanical properties is needed for the widespread applications of the green composites. Thereby, future research might also attempt to improve the interfacial adhesion between fiber and the matrix.

\section{Acknowledgement}

The authors gratefully acknowledge the financial support of the GITAM University and University Grants Commission. 


\section{References}

Arbeliaz A, Fernandez B, Valea A, Mondragon I. 2006. Mechanical properties of short flax bundle/poly (caprolactone) composites: Influence of matrix modification and fiber content. Carbohydrate Polymers, Vol. 64, pp. 224-232.

Avella M, Gaceva GB, Buzarovska A, Errico ME, Gentile G, Grozdanov A. 2007. Poly (3-hydroxybutyrate-co-3hydroxyvalerate)-based biocomposites reinforced with kenaf fibers. Journal of Applied Polymer Science, Vol. 104, pp. 3192 3200 .

Basavarajappa S, Chandramohan G, Ashwin M, Prabu M, Mukund. 2006. Analysis of burr formation during drilling of hybrid metal matrix composites using design of experiments. International Journal of Machining and Machinability of Materials, Vol. 1, No.4, pp. 500-510.

Bodros E, Pillin I, Montrelay N, Baley C. 2007. Could biopolymers reinforced by randomly scattered flax fiber be used in structural applications, Composite Science and Technology, Vol. 67, pp. 462-470.

Bernard M, Khalina A, Ali A, Janius R, Faizal M, Hasnah KS, Sanuddin AB. 2011. The effect of processing parameters on the mechanical properties of kenaf fiber plastic composite. Materials and Design, Vol. 32, No.2, pp.1039-1043.

Garkhail SK, Meurs E, Beld T, Peijs T. 1999. Thermoplastic composites based on biopolymers and natural fibers. $12^{\text {th }}$ International conference on composite materials, Paris, pp. 1175.

$\mathrm{Ku} \mathrm{H}$, Wang H, Pattarachaiyakoop N, Trada M. 2011. A review on the tensile properties of natural fiber reinforced polymer composites. Composites part B: Engineering, Vol. 42, No.4, pp. 856-573.

LaMantia FP and Morreale M. 2011. Green composites: A brief review. Composites part A: Applied Science and Manufacturing, Vol. 42, No.6, pp. $579-588$.

Ochi S. 2006. Development of high strength biodegradable composites using manila hemp fiber and starch based biodegradable resin. Composites part A: Applied science and manufacturing, Vol. 37, pp. 1879-1883.

Ochi S. 2008. Mechanical properties of kenaf fibers and kenaf/PLA composites. Mechanics of materials, Vol. 40, pp. 446-452.

Oksman K, Skrifvars M, Selin JF. 2003. Natural fibers as reinforcement in polylactic acid (PLA) composites. Composites Science and Technology, Vol. 63, pp. 1317-1324.

Mahapatra SS, Patnaik A. 2007. Optimization of wire electrical discharge machining (WEDM) process parameters using Taguchi method. International Journal Advanced Manufacturing Technology, Vol. 34, pp. 911-925.

Mohanty AK, Mubarak AK, Hinichsen G. 2000. Surface modification of jute fiber and its influence on performance of biodegradable jute fabric/ Bipol composites. Composite Science and Technology. Vol. 60, pp. 1115-1124.

Medina L, Schledjewski R, Schlarb AK. 2009. Process related mechanical properties of press molded natural fiber reinforced polymers. Composites Science and Technology, Vol. 69, No.9. pp. 1404-1411.

Patnaik A, Satapathy A, Mahapatra SS and Dash RR. 2008. Modeling and prediction of erosion response of glass fiber reinforced polyster fly ash composites. Journal Reinforced Plastics and Composites, Vol. 28, No. 5, pp. 513-536.

Patnaik A, Satapathy A, Mahapatra SS. 2009. Study on erosion response of hybrid composites using Taguchi experimental design. Journal of Engineering Materials and Technology. Vol. 131, pp. 031011-1-16.

Placket D, Anderson TL, Pedersen WB, Nielson L. 2003. Biodegradable composites based on L-Polylactide and jute fibers. Composites Science and Technology, Vol. 63, pp. 1287-1296.

Rezaei M, Ebrahimi NG, Shirzad A. 2006. Study on mechanical properties of UHMWPE/PET composites using robust design. Iranian Polymer Journal, Vol. 15, No.1, pp. 3-12.

Rassmann S, Reid RG, Paskaramoorthy R. 2010. Effects of processing conditions on the mechanical and water absorption properties of resin transfer moulded kenaf fiber reinforced polyester composite laminates. Composites part A: Applied Science and Manufacturing, Vol. 41, No.11, pp. 1612-1619.

Shibata S, Cao Y, Fukumoto I. 2008. Flexural modulus of the unidirectional and random composites made from biodegradable resin and bamboo and kenaf fibers. Composites part A: Applied science and manufacturing, Vol. 39, pp. 640 -646.

Sreekumar PA, Joseph K, Unnikrishnan G, Thomas S. 2011. Surface-Modified Sisal Fiber-Reinforced Eco-Friendly Composites: Mechanical, Thermal, and Diffusion Studies. Polymer composites, Vol. 32, No.1, pp. 131-138.

Sawpan M A, Pickering KL, Fernyhough A. 2011. Effect of various chemical treatments on the fiber structure and tensile properties of industrial hemp fibers. Composites part A: Applied Science and Manufacturing, Vol. 42, No.8, pp. 888 -895.

Takagi H, Asano A. 2008. Effects of processing conditions on flexural properties of cellulose nanofiber reinforced green composites. Composites part A: Applied Science and Manufacturing, Vol. 39, pp. 685-689.

Velde K, Baetens E. 2000. Thermal and mechanical properties of flax fibers for composite reinforcement. Proceedings of $3^{\text {rd }}$ International wood and natural fiber composites, Germany.

\section{Biographical notes}

G. Bhanu Kiran is a Assistant professor in the Department of Mechanical Engineering, GITAM Institute of Technology. GITAM University, Visakhapatnam India. He has published 6 International research papers and has guided 8 PG projects. His research area is Biocomposites, 
Dr. K.N.S.Suman is a Professor in the Department of Mechanical Engineering, College of Engineering, Andhra university, Visakhapatnam, India. He has more than 10 years of experience in teaching and research. Currently working for UGC, New Delhi sponsored, research project on 'Development of high strength biodegradable composite materials'. He has published 25 research papers in various national and International journals and conferences. His current areas of research are engineering applications of polymer Nano composites.

Dr. N.Mohan Rao is a Professor in Department of Mechanical Engineering, Jawaharlal Nehru Technological University, Kakinada, India. At present, a total of 25 research papers are published in various national and International journals and conferences. His current areas of research are Robotics and Optimization.

R. Uma Maheswara Rao is a Associate professor in the Department of Mechanical Engineering, GMR Institute of technology, Rajam, India. He has published 3 international research papers. His research interests include optimization and nano composites.

Received May 2011

Accepted June 2011

Final acceptance in revised form July 2011 